\title{
A porcine polytrauma model with two different degrees of hemorrhagic shock: outcome related to trauma within the first $48 \mathrm{~h}$
}

\author{
D. Eschbach ${ }^{1 *}$ (D) T. Steinfeldt ${ }^{2}$, F. Hildebrand ${ }^{4}$, M. Frink ${ }^{1}$, K. Schöller ${ }^{3}$, M. Sassen ${ }^{2}$, T. Wiesmann², F. Debus ${ }^{1}$, \\ N. Vogt ${ }^{3}$, E. Uhl ${ }^{3}$, H. Wulf 2 , S. Ruchholtz ${ }^{1}$, H. C. Pape ${ }^{4}$ and K. Horst ${ }^{4}$
}

\begin{abstract}
Background: An animal polytrauma model was developed, including trunk and extremity injuries combined with hemorrhagic shock and a prolonged post-traumatic phase. This could be useful for the assessment of different therapeutic approaches during intensive care therapy.

Methods: A standardized polytrauma including lung contusion, liver laceration and lower leg fracture was applied in 25 pigs. They underwent controlled haemorrhage either with a blood volume loss of $45 \%$ and a median arterial pressure (MAP) $<30 \mathrm{mmHg} / 90 \mathrm{~min}$ (group $\mathrm{L}, n=15$ ) or a $50 \%$ blood loss of and an MAP $<25 \mathrm{mmHg} / 120$ min (group $H, n=10$ ). Five non-traumatized pigs served as a control (group C). Subsequently, intensive care treatment was given for an observational period of $48 \mathrm{~h}$.

Results: Both trauma groups showed signs of shock and organ injury (heart rate, MAP and lactate). The frequency of cardiopulmonary resuscitation (CPR) and lung injury was directly related to the severity of the haemorrhagic shock (CPR - group L: 4 of 15 pigs, group H: 4 of 10 pigs; Respiratory failure — group L: 3 of 13, group H: 3 of 9. There was no difference in mortality between trauma groups.

Conclusion: The present data suggest that our model reflects the mortality and organ failure of polytrauma in humans during shock and the intensive care period. This suggests that the experimental protocol could be useful for the assessment of therapeutic approaches during the post-traumatic period.
\end{abstract}

Keywords: Experimental animal model, Porcine polytrauma model, Combined trauma model

\section{Background}

There are several animal models for trauma and organ failure research, but a model mimicking real polytrauma, including simultaneous organ and musculoskeletal injuries, has not yet been described. Recently we described an animal experimental model of multi-system injury, consisting of blunt chest trauma, penetrating abdominal trauma and pressure-controlled hemorrhagic shock in pigs with an observational period of $16 \mathrm{~h}$ [1]. This model lacked a musculoskeletal injury component, and the

\footnotetext{
*Correspondence: eschbach@med.uni-marburg.de

${ }^{1}$ Center for Orthopaedics and Trauma Surgery; University Hospital

Giessen and Marburg, Marburg, Germany

Full list of author information is available at the end of the article
}

study period was short by clinical standards. Most models lack information on the latter, i.e., 15-h-plus, posttraumatic phase [2]. Indeed, most studies of new early phase treatments do not adequately reflect the clinical situation in humans.

The aim of the present experiment was to establish a porcine model of hemorrhagic shock, multi-organ injury and musculoskeletal trauma with a prolonged observational period of $48 \mathrm{~h}$. To standardize treatment during the post-trauma period, management of temperature, cardiovascular complications, volume therapy, and the prevention and treatment of ventilator or trauma-associated lung complications were defined prior to the study. Moreover, we compared two different severities of hemorrhagic shock to identify the most appropriate trauma 
intensity with respect to the occurrence of traumarelated organ failure.

\section{Methods}

\section{Structural and financial investigation requirements}

The experimental setup was time consuming and resource intensive. The experiment took place 5 days a week for $24 \mathrm{~h}$ a day, over a period of 6 months. Seven physicians, one veterinarian, four students, one medical technician and one nurse anesthetist were trained for 6 weeks during the feasibility study. The animals were handled and fed by four members of the animal care team. We implemented an operational shift system, with six people present from 7:00 a.m. to 7:00 p.m. 3 days a week (Monday, Wednesday and Friday). This was for assessment of new animals or performance of euthanasia and standardized section. Three team members were present 2 days a week (Tuesday and Thursday) from 7:00 a.m. to 7:00 p.m., while two people were responsible for the night shift (7:00 p.m. to 7:00 a.m.). The night shift team included an experienced physician. The total study expenditure for animals and material resources amounted to approximately $€ 55,000$. Personal effort was borne by members of the four participating institutions.

\section{Animals}

The experimental procedures were approved by local authorities (Ref. 22/2013) Regional board, Giessen, Germany and the study was performed in compliance with the Helsinki convention for the use and care of animals and reported in consent with the ARRIVE guidelines [3]. In this study, 30 male pigs (Deutsche Landrasse) weighing $29.7-41.5 \mathrm{~kg}$ (median $34.6 \mathrm{~kg}$ ) were used. All pigs were male, aged 3-6 months, healthy and fasted for $12 \mathrm{~h}$ at the start of investigation. Pigs were delivered twice a week from a nearby animal breeding service.

\section{Experimental groups}

Five non-traumatized pigs served as controls (group C). Standardized polytrauma with a "low" blood loss was induced in 15 pigs (group L). In a second polytrauma group a "high" blood loss was induced and was applied in 10 pigs (group $\mathrm{H}$ ). The target median arterial pressure was to be maintained at least $5 \mathrm{mmHg}$ lower in group $\mathrm{H}$ by escalated hemorrhage and shock period was extended from 60 to $90 \mathrm{~min}$. Animals were randomly assigned to intervention or control groups.

\section{Instrumentation and measurements}

The animals were premedicated with diazepam $(1 \mathrm{mg} /$ $\mathrm{kg})$, ketamine $(20 \mathrm{mg} / \mathrm{kg})$ and atropine $(0.5 \mathrm{mg})$ intramuscularly. They were placed in the prone position and pre-oxygenated $\left(10 \mathrm{LO}_{2} / \mathrm{min}\right)$. After ear vein cannulation, anesthesia was induced with sufentanil and disoprivane followed by a continuous infusion (sufentanil $0.8 \mu \mathrm{g} / \mathrm{kg} / \mathrm{h}$, disoprivane $3-4 \mathrm{mg} \mathrm{kg} / \mathrm{h}$ ) during the entire study period of $48 \mathrm{~h}$. The animals were orotracheally intubated and given pressure-controlled ventilation with a tidal volume of $6-8 \mathrm{~mL} \mathrm{~kg}^{-1}$ (Draeger, Evita, Danvers, MA, USA), positive end-expiratory pressure (PEEP) of $5 \mathrm{~cm} \mathrm{H}_{2} \mathrm{O}, \mathrm{FiO}_{2}$ of 0.3 , and inspiration-toexpiration ratio (I:E) of 1:2. Respiratory rate was varied to achieve an endtidal $\mathrm{CO}_{2}$ less than $7.3 \mathrm{kPa}$. Ventilatory assessment was performed under control of blood gas analysis (BGA, ABL 700, Radiometer Copenhagen). A balanced saline solution (Ringer's acetate) was continuously infused at a rate of $2 \mathrm{~mL} / \mathrm{kg} / \mathrm{h}$. Hypovolemia was treated with a fluid bolus of $10 \mathrm{~mL} / \mathrm{kg}$. A single shot of cefuroxim $80 \mathrm{mg} / \mathrm{kg}$ was applied prior to the interventions.

The following catheters were inserted under aseptic conditions: an arterial PiCCO system (pulse contour cardiac output) in the left femoral artery, a central venous line via the right jugular vein (3 lumen HD, Arrow, PA, USA), a suprapubic urine catheter, and a two-lumen hemodialysis line was placed in the left femoral vein (two-lumen HD, 14Fr, $15 \mathrm{~cm}$, Arrow, PA, USA). Tracheotomy was then performed. All ventilator and hemodynamic parameters were monitored and recorded. Electrocardiogram, oxygen saturation, temperature and arterial pressure were monitored continuously.

\section{Experimental protocol}

Organ-specific outcome parameters are given in Table 1. The time schedule is depicted in Fig. 1. At baseline, $\mathrm{pCO}_{2}$ was adjusted at $40 \pm 5 \mathrm{mmHg}$ and temperature was kept $>37^{\circ} \mathrm{C}$. $\mathrm{FiO}_{2}$ was defined at $21 \%$ during the trauma period, simulating ambient air. The animal was placed on the right side. The right hind leg was placed into a dropweight device and $20 \mathrm{~kg}$ of plumb-cuboid were dropped guided from a height of $100 \mathrm{~cm}$ (Fig. 2). Afterwards blunt chest trauma of the right thorax (captive bolt stunner, direct contact on a panel $10 \times 10 \mathrm{~cm}$, upper layer of lead, lower layer of steel) was performed in the supine position, followed by laparotomy and laceration of the liver (caudal

\section{Table 1 Outcome parameters}

\begin{tabular}{ll}
\hline Lung & $\begin{array}{r}\mathrm{FiO}_{2}, \mathrm{pO}_{2}, \mathrm{pCO}_{2}, \text { macroscopic injury, } \\
\text { chest tubing, } \mathrm{pO}_{2} / \mathrm{FiO}_{2} \text { ratio }\end{array}$ \\
Cardiovascular system & $\mathrm{RR}, \mathrm{HF}, \mathrm{MAP}$ lactate, $\mathrm{BE}$, resuscitation \\
frequency, mortality & $\mathrm{AST}, \mathrm{ALT}$, creatinine, urinary output, \\
Liver/renal system & $\mathrm{AST} / \mathrm{ALT}$ ratio \\
Musculoskeletal system & $\mathrm{CK}$, myoglobin, AST \\
\hline
\end{tabular}



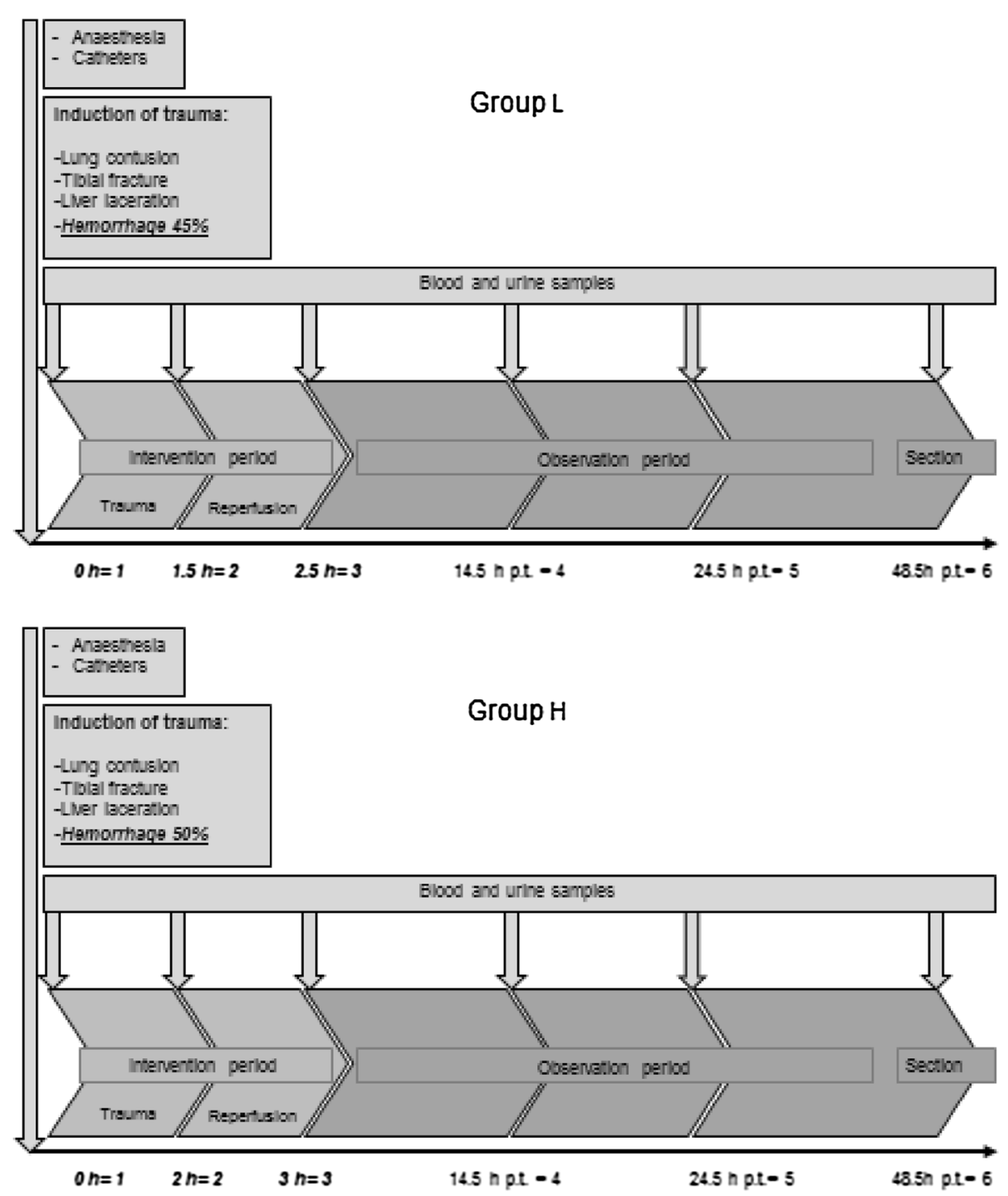

Fig. 1 Time flow in experimental setup of groups $L$ and $H$. Points of analysis of blood and urine samples are marked and differences in setup pointed out

lobe) by stabbing twice with a four-edged scalpel (Fig. 3). The consequent uncontrolled bleeding was addressed after $30 \mathrm{~s}$ with a tamponade, consisting of seven unfolded gauze compresses. Simultaneously, systemic hemorrhage was realized by draining up to $45 \%$ of estimated total blood volume (TBV) in group $\mathrm{L}$ and $50 \%$ in group $\mathrm{H}$, or until a mean arterial blood pressure of $30 \pm 5 \mathrm{~mm} / \mathrm{Hg}$ in group $\mathrm{L}$ and $25 \pm 5 \mathrm{~mm} / \mathrm{Hg}$ in group $\mathrm{H}$ was achieved. Blood loss was realized by taking repeated blood samples with a $50-\mathrm{mL}$ syringe using the two-lumen hemodialysis line that was placed at the left femoral vain (two-lumen HD, $14 \mathrm{Fr}, 15 \mathrm{~cm}$, Arrow, PA, USA). We aimed to measure the blood loss in the first 20-30 min, trying to keep the MAP at the required $25-30 \mathrm{mmHg}$ (with a minimum
MAP of $20 \mathrm{mmHg}$ ). This proved to be the critical MAP for achieving cardiac arrhythmia, often with irreversible cardiac arrest in previous feasibility studies. Hemorrhagic shock was maintained for 90 min in group $\mathrm{L}$ and 120 min in group $\mathrm{H}$.

Following the trauma period, fluid resuscitation was performed via warmed Ringer's acetate solution $(4 \times$ hemorrhagic volume/60 $\mathrm{min})$ to achieve physiological MAP and HR values. If needed, vasoactive drugs like noradrenaline were administered to keep MAP within physiological boundaries $(55-70 \mathrm{mmHg}$ ).

The intervention period was followed by an observation period of $46 \mathrm{~h}$ under standardized intensive care management (bedding, airway and volume management, 

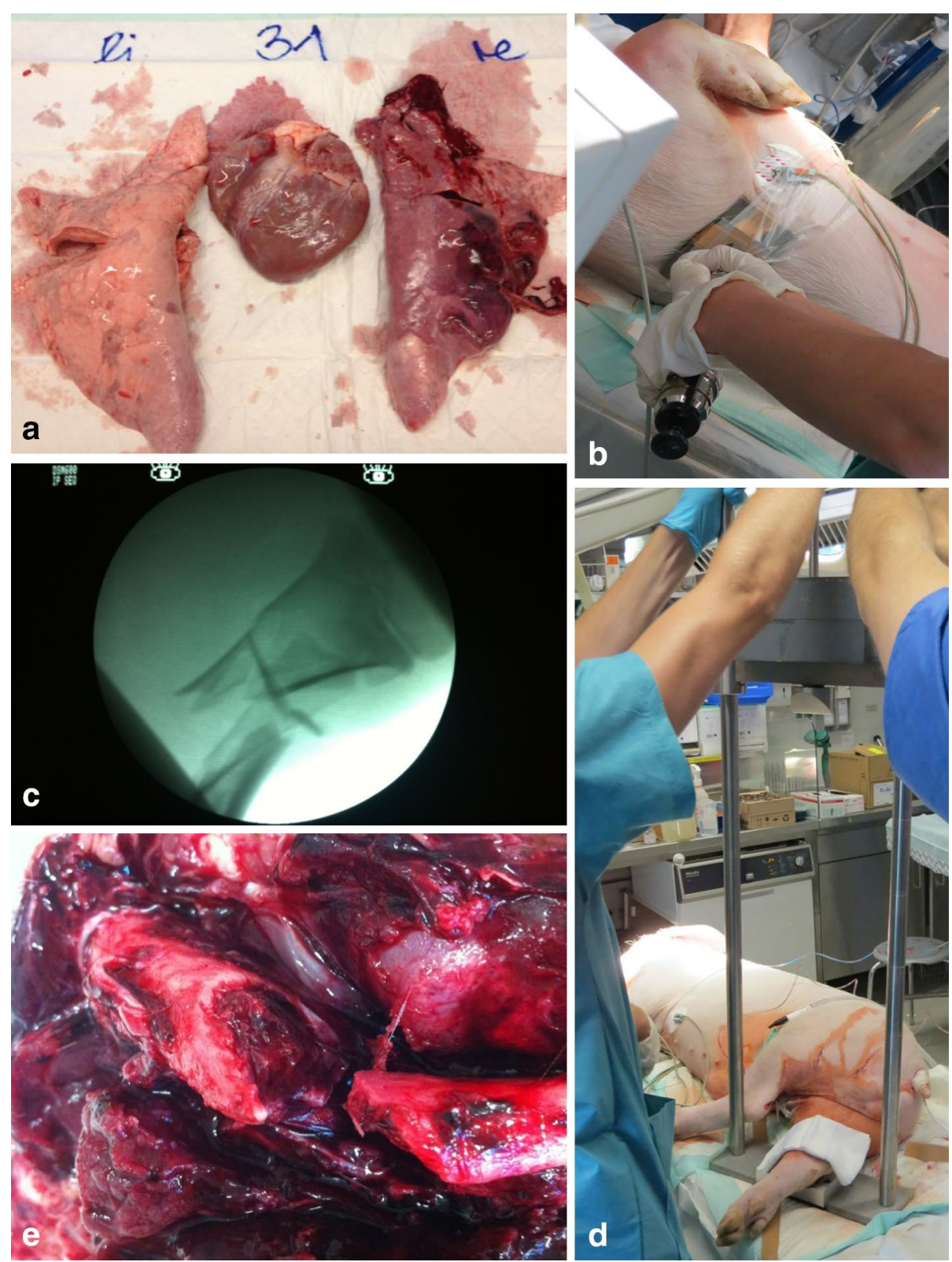

Fig. 2 Autopsy findings and experimental setup. a Right lung shows macroscopic tissue damage and hemorrhagic bullae. b Assessment during the performance of lung trauma. The captive bolt stunner is targeted towards the lead plate. c Fluoroscopy of right hind leg after fracture. $\mathbf{d}$ Dropweight gadgetry placed above the right hind leg to produce fracture. e Macroscopic findings in the fracture zone

temperature control). Complications were addressed according to current standards of emergency medicine and trauma surgery, such as recommendations made in the latest update of the European Resuscitation Council [4] as well Advanced Trauma Life Support (ATLS) protocols [5]. These allow standard techniques such as insertion of chest tubes for pneumothorax. Typical emergency medications (i.e., epinephrine, noradrenaline, amiodarone, midazolame, atropine) were given intravenously as required for life-threatening events (i.e., seizure, tension pneumothorax, ventricular fibrillation, cardiac arrest).

In case of CPR, the pig was turned on its right side for external cardiac massage (chest compressions at a rate of at least $100 / \mathrm{min}$, uninterrupted except for defibrillation or pulse checks). $\mathrm{FiO}_{2}$ was turned at 1.0, and suprarenine (1:10, $1 \mathrm{mg})$ was applied repetitively according to ERC 2010 guidelines. In case of ventricular fibrillation, amiodarone was administered $(3 \mathrm{~mL} / 150 \mathrm{mg})$, and external 

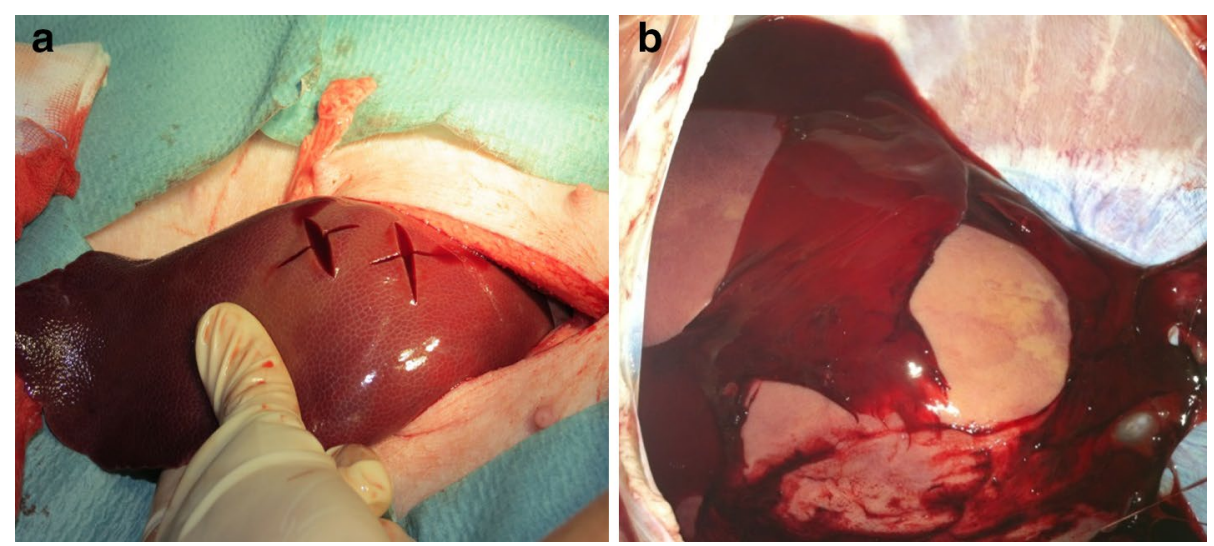

Fig. 3 Macroscopic presentation of liver laceration. a Liver traumatization, b coagulated blood covering the liver laceration after $48 \mathrm{~h}$ during section

electric shocks (150 J biphasic, Corpuls3, GS Elektromed. G. Stemple GmbH, D-86916 Kaufering) were applied. Resuscitation was terminated after $45 \mathrm{~min}$ without achieving ROSC.

Respiratory failure (RF) was defined as more than three blood gas analyses over more than $6 \mathrm{~h}$ post-trauma (and after $24 \mathrm{~h}$ of observation) showing a $\mathrm{PO}_{2} / \mathrm{FiO}_{2}$ ratio $<300$, PEEP $\geq 5$ in the absence of clinical or sonographic signs of severe left heart failure. Treatment was according to the ARDSnet guidelines [6].

Following the observation period, euthanasia was induced by enhancing anesthesia and applying an additional $100 \mu \mathrm{g}$ of sufentanil, $200 \mathrm{mg}$ of disoprivane, and $4 \mathrm{mg}$ of pancuronium. Afterwards, $60-100 \mathrm{~mL}$ of potassium chloride was administered until the occurrence of cardiac arrest.

\section{Sample collection}

We defined six points of analysis for arterial blood and urine sampling (Fig. 1): baseline, at the beginning of the experiment, immediately before the induction of trauma (1), after trauma period (2), after reperfusion (3), at $14.5 \mathrm{~h} \mathrm{(4)}, 24.5 \mathrm{~h}(5)$ and $48.5 \mathrm{~h}(6)$ post-trauma. All samples were centrifuged, $\left(4^{\circ} \mathrm{C}, 5 \mathrm{~min}, 4000 \mathrm{rpm}\right)$, deep frozen and stored at $-80^{\circ} \mathrm{C}$.

Euthanasia was followed by a standardized section. Tissue samples were taken from brain, lungs, heart, liver, kidneys, adrenal gland, fracture zone and ambient muscle. Half of the tissue samples were immersed in formalin $4 \%$ and afterwards coated with paraffin wax; the other half were shock frosted in liquid nitrogen and stored at $-80^{\circ} \mathrm{C}$.

\section{Training and preparation prior to investigation}

In agreement with our animal welfare committee we obtained permission to execute a preceding feasibility study using 10 animals. The aim was to develop methods of lower limb fracture in combination with surrounding trauma, and to test the feasibility of an extended study period. This study was required for the training of participating staff and the determination of material and personal requirements. Results of this feasibility study were not included in this study.

\section{Statistical analysis}

Statistics were compiled using Excel ${ }^{\circledR}$ (Microsoft 2010) and SPSS $^{\circledR}$ (PASW Statistics 22). The KolmogorovSmirnov Test was used to test for normal distribution of data; homogeneity of variance was tested by the Levene's Test.

Group differences were tested by the non-parametric Kruskal-Wallis Test. Then the individual groups were subjected to subsequent post hoc analysis with the Mann-Whitney $U$ test, Chi-square test or Fisher's exact test; the alpha was adjusted using the Bonferroni method to compare the intervention groups $\mathrm{H}$ and $\mathrm{L}$ and the control group. Thus, $p<.025$ was required for all tested variables concerning the three groups. Data are presented as medians and IQRs or ranges.

\section{Results}

\section{Basic data}

Basic data are given in Table 2. All control animals survived and none required cardiopulmonary resuscitation. In group L, CPR was needed in four of 15 animals; the return of spontaneous circulation (ROSC) was observed in two animals. The underlying cause in both cases was ventricular tachycardia leading to ventricular fibrillation and pulselessness at 24.18 and $35.5 \mathrm{~h}$. Two animals died after $\mathrm{CPR}$ in the first $12 \mathrm{~h}$ of the investigation $(1.48,6.05 \mathrm{~h})$ following ventricular fibrillation in the wake of uncontrolled 
Table 2 Baseline data

\begin{tabular}{|c|c|c|c|c|}
\hline & Group C & Group L & Group H & $p$ \\
\hline Number of animals & 5 & 15 & 10 & \\
\hline Weight (kg) & $35.1(\mathrm{IQR} 8.25)$ & 32.1 (IQR 4.7) & 36.1 (IQR6.03) & n.s. \\
\hline Mortality (\%) & 0 & $13(N=2)$ & $10(N=1)$ & n.s. \\
\hline CPR (\%) & 0 & $26.67(N=4)$ & $40(N=4)$ & n.s. \\
\hline Chest tube (\%) & 0 & $40(N=6)$ & $30(N=3)$ & n.s. \\
\hline Hemorrhage of total blood volume (\%, TBV) & - & $43.8(\operatorname{IQR} 3,9)$ & 49.5 (IQR 4.6) & $\begin{array}{l}\text { G.C/G.L } p \leq 0.001 \\
\text { G.C/G.H } p \leq 0.001 \\
\text { G.L/G.H } p=0.005\end{array}$ \\
\hline $\min \mathrm{MAP}(\mathrm{mm} / \mathrm{Hg})$ & $68.4(\mathrm{IQR} 25)$ & 29 (IQR 9) & $22.5(\mathrm{IQR} 5)$ & $\begin{array}{l}\text { G.C/G.L } p \leq 0.001 \\
\text { G.C/G.H } p \leq 0.001 \\
\text { G.L/G.H } p=0.005\end{array}$ \\
\hline Max HR during trauma period (bpm) & 95 (IQR 26) & 205(IQR 28) & 214 (IQR 42.5) & $\begin{array}{l}\text { G.C/G.L } p \leq 0.001 \\
\text { G.C/G.H } p \leq 0.001 \\
\text { G.L/G.H } p=0.42\end{array}$ \\
\hline Respiratory failure (\%) & 0 & $23(N=3)$ & $30(N=3)$ & $\begin{array}{l}\text { G.C/G.L } p=0.4 \\
\text { G.C/G.H } p=0.081 \\
\text { G.L/G.H } p=0.65\end{array}$ \\
\hline Arterial lactate post-trauma $(\mathrm{mmol} / \mathrm{L})$ & $1.2(\mathrm{IQR} 0.5)$ & $3.2(\mathrm{IQR} 2.0)$ & $3.9(\mathrm{IQR} 3.4)$ & $\begin{array}{l}\text { G.C/G.L } p \leq 0.001 \\
\text { G.C/G.Hp }=0.029 \\
\text { G.L/G.H } p=0.367\end{array}$ \\
\hline BE post-trauma (mmol/L) & 6.7 (IQR 2.34) & 1.5 (IQR 3.01) & $1.0(\mathrm{IQR})$ & $\begin{array}{l}\text { G.C/G.L } p \leq 0.001 \\
\text { G.C/G.Hp }=0.004 \\
\text { G.L/G.Hp }=0.701\end{array}$ \\
\hline De Ritis ratio $24.5 \mathrm{~h}$ & $0.82(\mathrm{IQR} 0.7)$ & 1.78 (IQR 0.89) & $3.8(\mathrm{IQR} 5.5)$ & $\begin{array}{l}\text { G.C/G.L } p \leq 0.733 \\
\text { G.C/G.H } p=0.092 \\
\text { G.L/G.H } p=0.030\end{array}$ \\
\hline De Ritis ratio $48.5 \mathrm{~h}$ & $1.1(\mathrm{IQR} 0.9)$ & 2.06 (IQR 2.3) & $3.3(\operatorname{IQR} 3.2)$ & $\begin{array}{l}\text { G.C/G.L } p \leq 0.193 \\
\text { G.C/G.Hp }=0.116 \\
\text { G.L/G.H } p=0.330\end{array}$ \\
\hline
\end{tabular}

Sampled data are given as median and IQR. Group differences were tested by the non-parametric Kruskal-Wallis test. Individual groups were subjected to subsequent post hoc analysis with the Mann-Whitney $U$ test/Fisher's exact test. $p<0.025$ was considered statistically significant

bleeding. In group $\mathrm{H}$, four animals were resuscitated, all during the intervention period; ROSC was obtained in three. Three had ventricular fibrillation, one further developed a tension pneumothorax with hypotension and asystole.

\section{Trauma severity}

The severity of the trauma was confirmed by posttrauma serum lactate levels and a base deficit. In group $\mathrm{L}$, lactate reached a group median of $3.2 \mathrm{mmol} / \mathrm{L}$ (IQR 2.0); $3.9 \mathrm{mmol} / \mathrm{L}$ (IQR 3.4) in group H. It was $1.2 \mathrm{mmol} / \mathrm{L}$ (IQR 0.5) (Table 2) in group C. After trauma and following resuscitation, lactate in trauma groups was significantly elevated compared to sham group (Lab. 2/3 Fig. 4). Looking at lactate between trauma groups, group $\mathrm{H}$ lactate was significantly greater than group $\mathrm{L}$ after 30 and $60 \min (p=0.008 ; p=0.017)$, but there were no significant differences between trauma groups post-trauma. Lactate and $\mathrm{BE}$ were similar in all three groups after 10-12 $\mathrm{h}$ and over during the remaining investigation period (Fig. 4). BE was significantly less in the trauma groups than the controls during following trauma period (G.C/G.L $p \leq 0.001$ G.C/G.H $p=0.004$ ), but did not differ comparing group L and group H (G.L/G.H $p=0.701$ ) (Table 2). The three animals that did not survive all had $\mathrm{BE} \leq-8$ (group $\mathrm{L}-8.2$ and -9 , group $\mathrm{H}:-8.2 \mathrm{mmol} / \mathrm{L}$ ).

\section{Thoracic trauma}

Our blunt thoracic trauma caused visible macroscopic tissue damage (Fig. 2); $\mathrm{pO}_{2}$ levels did not differ during trauma $(p=0.119)$. $\mathrm{pCO}_{2}$ ranged $47-53 \mathrm{~mm} / \mathrm{Hg}$ in group C, $47-50 \mathrm{~mm} / \mathrm{Hg}$ in group $\mathrm{L}$ and $43-49 \mathrm{~mm} / \mathrm{Hg}$ in group $\mathrm{H}$.

Three of 13 pigs in group L and three of nine in group $\mathrm{H}$ developed respiratory failure during the final $24 \mathrm{~h}$. The course of $\mathrm{pO}_{2} / \mathrm{FiO}_{2}$ ratio and arterial blood gas analysis is given in Fig. 5.

Clinical suspicion of pneumothorax (subcutaneous emphysema and decreased vital capacity) necessitated chest drainage in six pigs in group $\mathrm{L}$ and three in group $H$. Differences were not statistically significant. No respiratory problems were observed in group $\mathrm{C}$. 

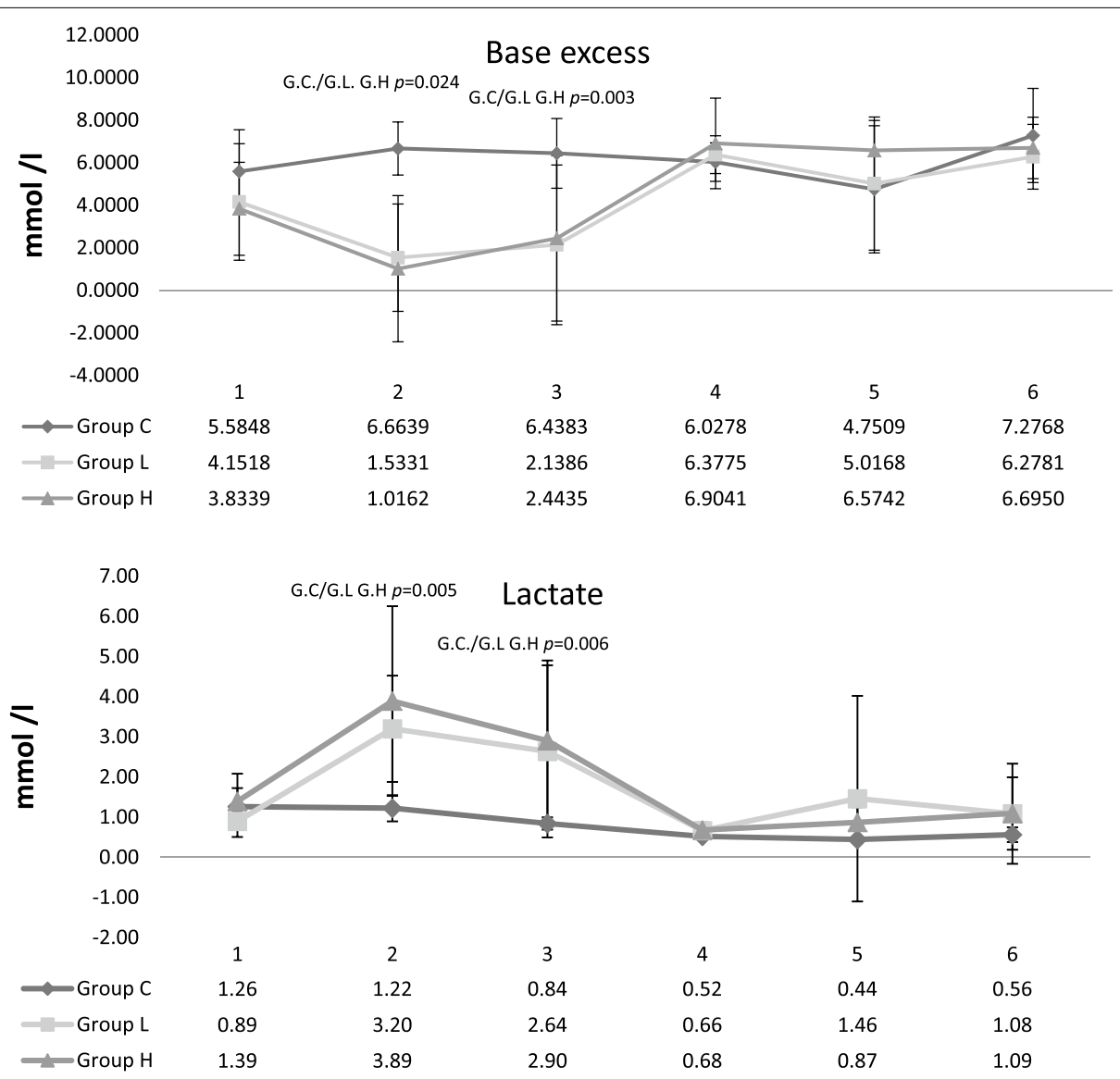

Fig. 4 Post-traumatic arterial base excess and lactate concentrations. 1 Pre-trauma, 2 after trauma, 3 after reperfusion, 4 after 14.5 h, 5 after 24.5 h, 6 after 48.5. Sampled data are given as median and IQR. Group differences were tested by the non-parametric Kruskal-Wallis Test, individual groups were subjected to subsequent post hoc analysis with the Mann-Whitney $U$ test and Fisher's exact test. $p<0.025$ was considered statistically significant

\section{Cardiovascular system}

Blood was drawn in the first 30 min of trauma. In the 15 pigs of group L, median blood loss was $43.8 \%$ (IQR 3.9) of TBV, minimal median MAP reached 29 (IQR 9) $\mathrm{mm} /$ $\mathrm{Hg}$ and group maximum median heart rate was 205 (IQR 28) during trauma period. In group $H, 49.5 \%$ (IQR 4.6) of TBV was drawn, and the minimal median MAP was $22.5 \mathrm{~mm} / \mathrm{Hg}$ (IQR 5). Group $\mathrm{H}$ maximum median heart rate was 214 (IQR 42.5) during shock; group $C$ remained in the physiological range of MAP and heart rate. Heart rate was significantly increased in both trauma groups during trauma period. Following the reperfusion period, MAP reached physiological levels and was kept there during the observation period. The need for at least transient noradrenaline administration for circulatory support showed no difference between trauma groups (group L $13 / 15$ animals, group $H 7 / 10$ animals; $P=0.653$ ). None of the control animals needed circulatory support. Hemoglobin concentrations were significantly less in trauma groups after reperfusion compared to controls and remained so during the whole investigation. Thrombocyte counts also decreased significantly in the trauma groups $(p=0.001)$ after reperfusion and remained low after $48.5 \mathrm{~h}$ ( $p=0.02)$ (Fig. 6). After $48.5 \mathrm{~h}$ the thrombocyte count in group $\mathrm{H}$ was even significantly lower than in group $\mathrm{L}(p=0.013)$.

\section{Hepatorenal system}

AST concentrations increased slightly over the time in all three groups, but only significantly after $24 \mathrm{~h}$ in group $\mathrm{H}(p \leq 0.02)$ compared to controls (Fig. 7). There was no difference between trauma groups. The AST/ALT ratio was 1.78 (IQR 0.89) in group L and 3.8 (IQR 5.5) in group $\mathrm{H}$ after $24.5 \mathrm{~h}(p=0.030)$; after $48.5 \mathrm{~h}$ it was 2.06 (IQR 2.3 ) and 3.3 (IQR 3.2) ( $p=0.33)$. In six of 13 animals in group $\mathrm{L}$ and 5 of 7 in group $\mathrm{H}$ (two measurements failed because of hemolysis) AST more than tripled by the end of study period. 
600
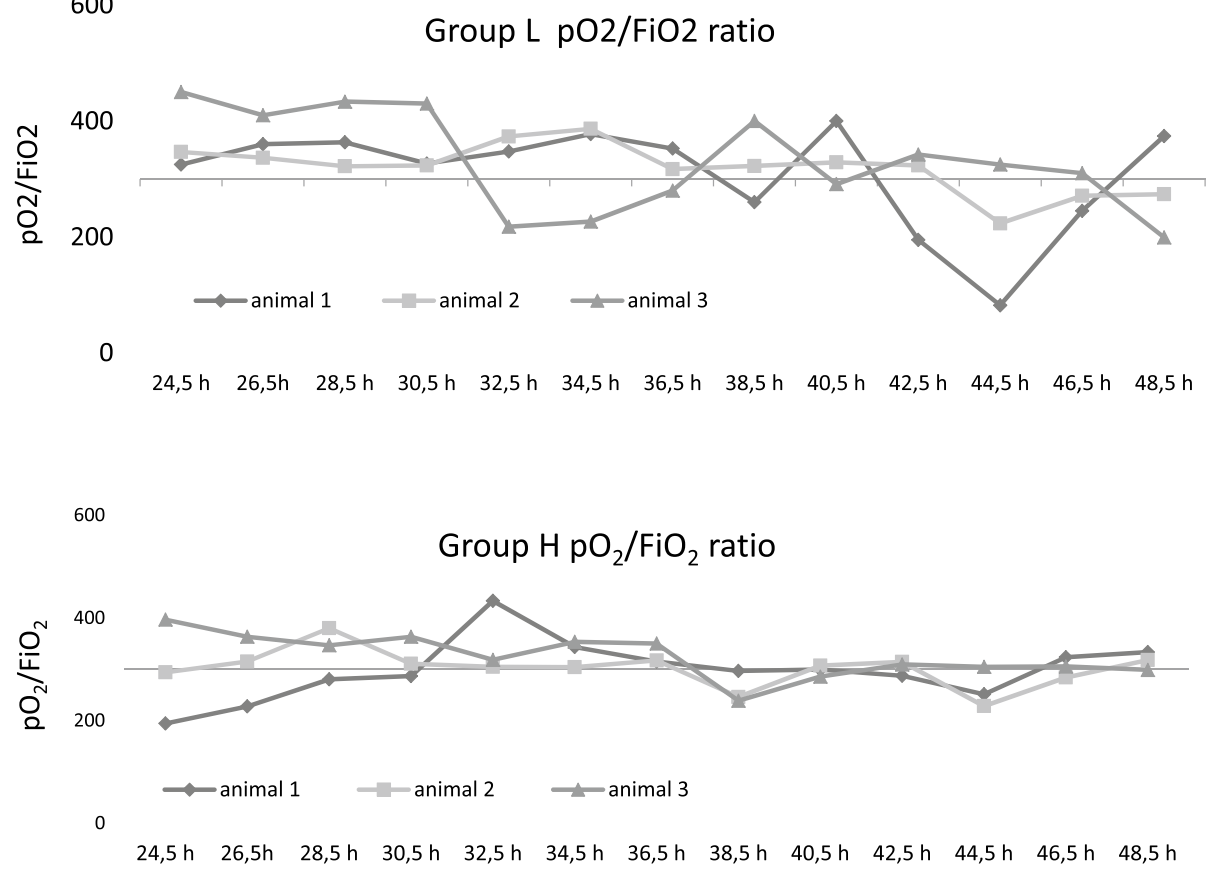

Fig. 5 Clinical course of $\mathrm{pO}_{2} / \mathrm{FiO}_{2}$ ratio during the last $24 \mathrm{~h}$ of observation. Arterial $\mathrm{pO}_{2}$ was measured every $2 \mathrm{~h}$ by blood gas analysis (BGA, ABL700, Radiometer Copenhagen)

In one animal of group L, liver lacerations bled for the first hour after packing and required suturing and repacking. The bleeding was localized by sonographic examination following an unexplained prolonged tachycardia after the reperfusion period, which led to detection of free fluid in the abdomen (Fig. 7).

As measured by creatinine clearance, renal function was significantly impaired immediately after trauma (G.C/G.L $p=0.002$ ) (Fig. 8), but normalized over time and was not greater than in group $C$ at the end of investigation. Urinary output also did not differ between groups, all groups having reduced their output after induction of anesthesia but normalized over time.

\section{Musculoskeletal system}

All fractures were grade II according to Gustilo, Mendoza and Williams [7]. After $14.5 \mathrm{~h}$ serum CK was significantly increased in both trauma groups $(p=0.017)$ (Fig. 8); later it increased even in group C. Medians were $>3000 \mathrm{U} / \mathrm{L}$ in group $\mathrm{C},>5000 \mathrm{U} / 1$ in group $\mathrm{L}$ and $>7000 \mathrm{U} / \mathrm{L}$ in group $\mathrm{H}$ but did not differ statistically significantly at the end of investigation. Myoglobin concentrations also significantly increased in the trauma groups after the first $14.5 \mathrm{~h}$. Later, in groups $\mathrm{C}$ and $\mathrm{L}$ it remained roughly constant, but group $\mathrm{H}$ exhibited a further, non-significant increase in myoglobin during the second $24 \mathrm{~h}$.

\section{Discussion}

We have devised a porcine polytrauma model that reflects the mortality and organ failure of polytrauma patients during shock and intensive care. We included two different severities of hemorrhagic shock. The severity of the trauma and its effects appeared to be reproducible.

Pre-clinical models are needed to develop new therapies for trauma. These are mostly porcine because of the similarity to humans [8-10]. A discussion of current models took place at a Military Medicine Workshop on Animal Models in Hemorrhage and Resuscitation Research [11], in particular the question of a reproducible trauma/hemorrhage model. The key points are as follows: (a) the need for volume- or pressure-controlled models that can allow uncontrolled bleeding, (b) surgical manipulation, e.g., soft tissue injury coincident with hemorrhage as in clinical situations, (c) significant soft tissue injury to better represent the post-injury inflammatory state, (d) a controllable degree of hypotension to lead to poor outcomes and (e) a model simulating battlefield trauma rather than one designed to meet a specific scientific goal $[2,11]$. Furthermore, it was also agreed that reproducible trauma and hemorrhage are key factors and that the duration of hemorrhagic shock has to mimic the clinical situation. The pre-clinical period is 60-80 min in Germany [12]. 


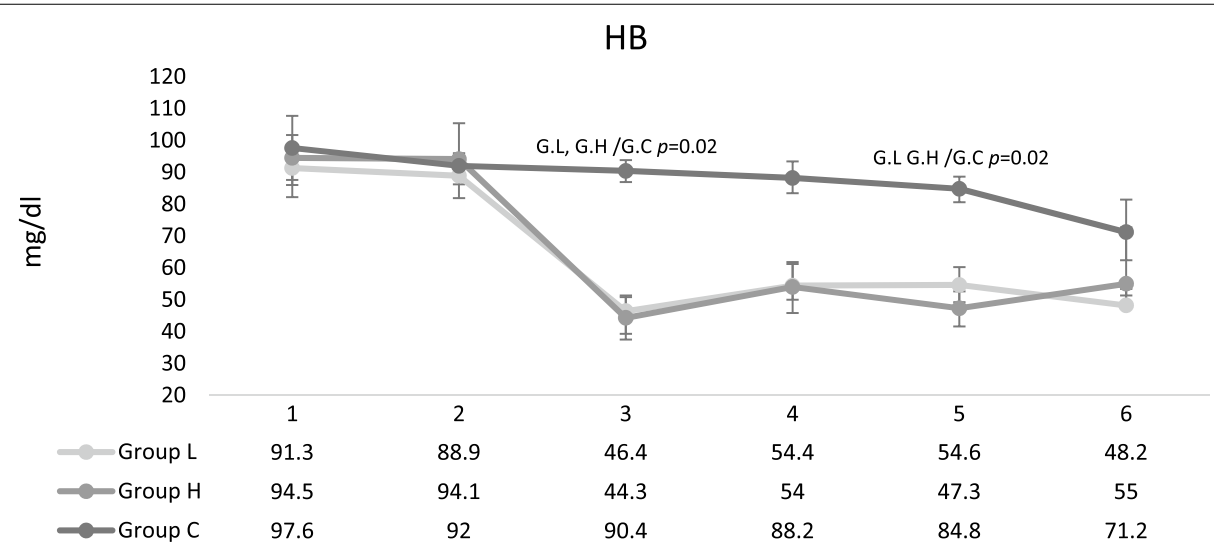

Thrombocytes

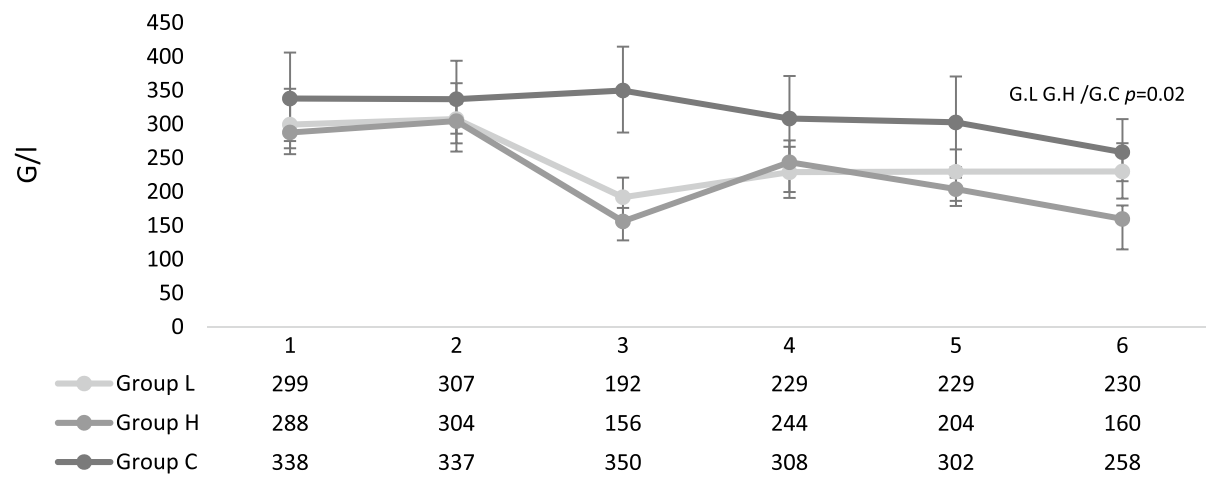

Fig. 6 Course of hemoglobin $(\mathrm{Hb})$ and thrombocyte concentrations during the experiment. 1 Pre-trauma, 2 after trauma, 3 after reperfusion, 4 after 14.5 h, 5 after 24.5 h, 6 after 48.5. Sampled data are given as median and IQR. Group differences were tested by the non-parametric Kruskal-Wallis test, individual groups were subjected to subsequent post hoc analysis with Mann-Whitney $U$ test and Fisher's exact test. $p<0.025$ was considered statistically significant

In 2012, we presented a porcine multi-system injury model of combined chest and abdominal trauma with hemorrhagic shock, including an observation period of $15.5 \mathrm{~h} \mathrm{[1]}$. It was shown to be reproducible and fulfilled many of the above criteria. Because of the need for studies including a longer observation period under intensive care conditions [13-15], we included a fracture of the right hind leg, and extended the study period to $48.5 \mathrm{~h}$ under intensive care conditions. Two grades of hemorrhage were achieved during our investigation. As no previous studies used a similar time period combined with simultaneous trauma of similar severity, we gradually tested the limits of feasibility. Since we already knew, based on previous investigation that it worked at least for $15 \mathrm{~h}$, we started with a hemorrhage of $45 \%$ of total blood volume for $90 \mathrm{~min}$ and extended this hemorrhage to a $50 \%$ loss of total blood volume and 120 min of shock, as described above. In addition to survival rates and resuscitation frequencies, we used lactate and $\mathrm{BE}$ during the trauma period as outcome parameters for trauma severity. In the early trauma period metabolic acidosis is accompanied by increased plasma lactate, reflecting inadequate tissue oxygen delivery [16]. Previous studies assessed the physiological plasma lactate concentration in Landrace/Pietrain crossbred animals at $1.1 \mathrm{mmol} / \mathrm{L}$ [17]. These correlate to the plasma lactate concentrations in group $\mathrm{C}$, suggesting that the increased lactate levels in group $\mathrm{L} / \mathrm{H}$ realistically represent severe trauma. There is a strong correlation between early serum lactate and mortality in trauma patients [18]. Lactate values similar to ours, ranging from about $2.5-4.0 \mathrm{mg} / \mathrm{dl}$, were associated with a mortality of $6.4 \%$. Our mortality was similar, although data have to be carefully interpreted because of the inter-species differences. Both trauma groups showed significantly decreased $\mathrm{BE}$ during the whole trauma and reperfusion period, suggesting a significant degree of metabolic acidosis. Animals with a BE less than -8 died within $3 \mathrm{~h}$. It is described, that base excess less than -6 

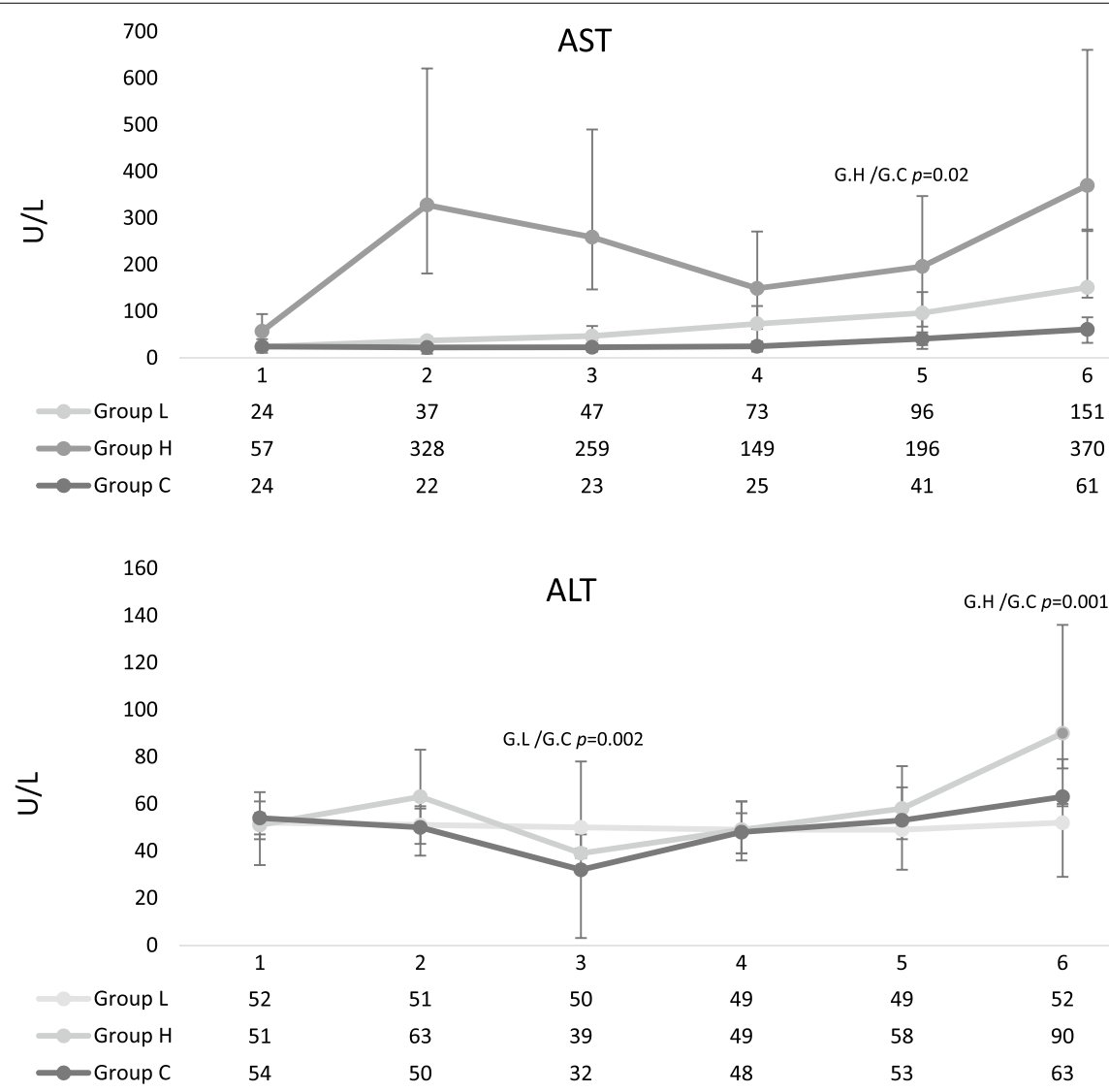

Fig. 7 Serum AST and ALT concentrations. 1 Pre-trauma, 2 after trauma, 3 after reperfusion, 4 after 14.5 h, 5 after 24.5 h, 6 after 48.5 . Sampled data are given as median and IQR. Group differences were tested by the non-parametric Kruskal-Wallis test, individual groups were subjected to subsequent post hoc analysis with the Mann-Whitney $U$ test and Fishers' exact test. $p<0.025$ was considered statistically significant. AST norm $\leq 35 \mathrm{I} / \mathrm{U}$, ALT norm $\leq 68 \mathrm{U} / \mathrm{L}$

during the first $24 \mathrm{~h}$ of admission after trauma is associated with a higher risk of massive transfusion, coagulopathy, ARDS and mortality [16]. Accordingly, return towards baseline values obtained by the sham group after $10-12 \mathrm{~h}$ was interpreted as a result of successfully performed resuscitation in trauma groups.

Oxygenation during the acute trauma period did not differ significantly between groups, perhaps because we adjusted $\mathrm{CO}_{2}$ levels to about $45 \pm 5 \mathrm{~mm} / \mathrm{Hg}$ during observation period by regulating inspiration rate and pressure.

Some independent risk factors for the development of ARDS after blunt trauma include an injury severity score (ISS) $>25$, the presence of pulmonary contusion, a large transfusion requirement, hypotension on admission, and age $>65$ years [19]. Other studies have shown specific injury patterns, such as long bone fracture, to be independently associated [20]. Post-traumatic ARDS may occur early $(<48 \mathrm{~h})$ or late $(>48 \mathrm{~h})$. Early development is also associated with presentation in hemorrhagic shock; our trauma model provides the majority of these risk factors. Three animals of each trauma group showed some degree of respiratory impairment, but no ARDS. There were no differences in lung function between groups $\mathrm{L}$ and $\mathrm{H}$.

Porcine hemorrhage experimental models have focused on volume-controlled [18, 21, 22] or pressure-controlled [22-24] blood loss; however, both have their disadvantages. In a volume-controlled investigation, the degree of hypotension depends on many factors, at least in terms of the individual animal's response. Most volume-controlled studies deal with a loss of 30-50\% of TBV, with a mortality rate of up to $20 \%$ [25-28]. In most pressurecontrolled studies, an MAP between 30 and $45 \mathrm{mmHg}$ was generally maintained for $30-45 \mathrm{~min}$. This artificial control of blood pressure does not mimic the clinical situation, and the volume of exsanguination can be very variable. Therefore, a combination of volume and pressure control may best mimic the clinical situation. Induction of a well-defined and reproducible trauma that 

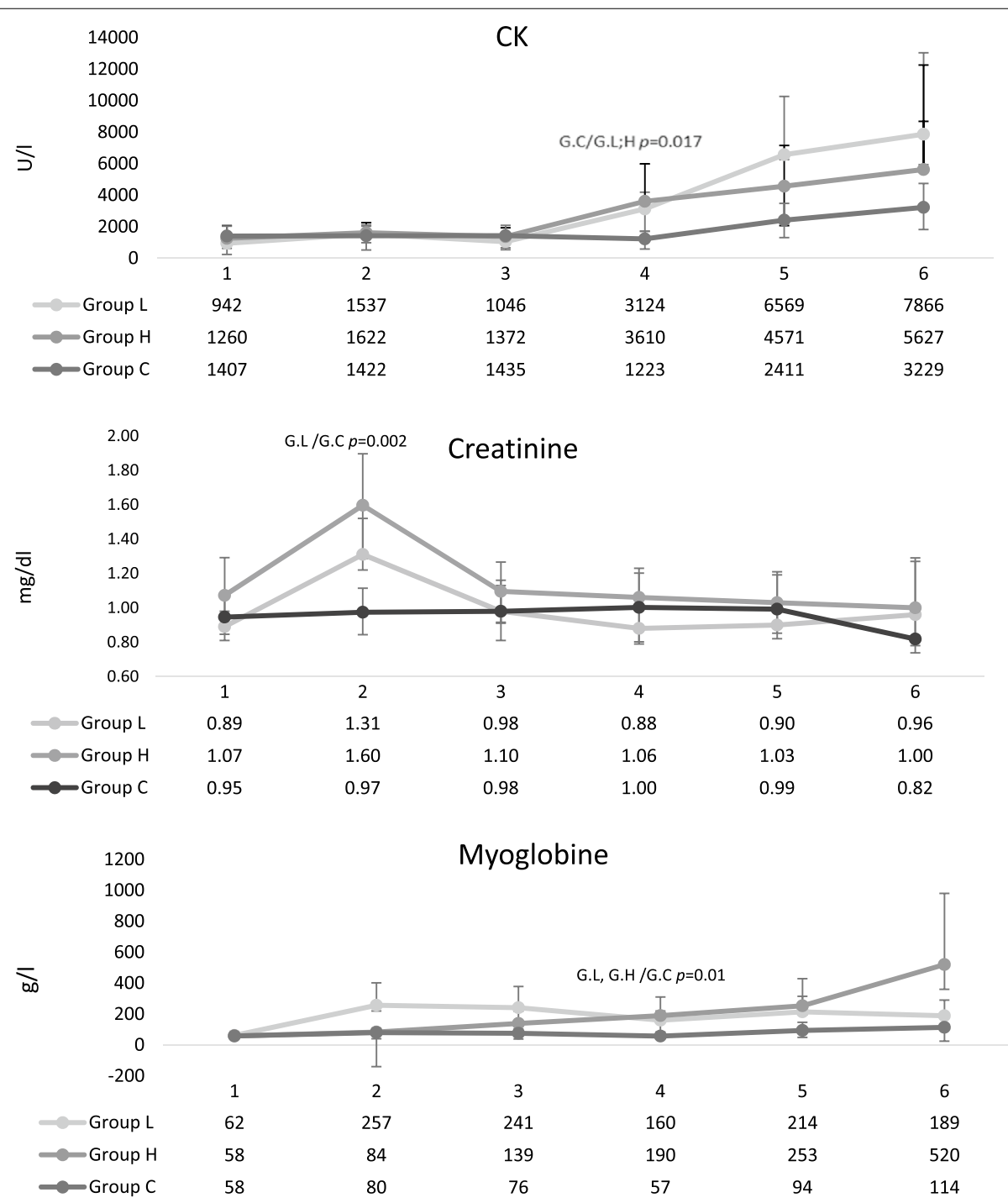

Fig. 8 Creatine kinase (CK), creatinine and myoglobin concentrations during the observation period. 1 pre-trauma, 2 after trauma, 3 after reperfusion, 4 after 14.5 h, 5 after 24.5 h, 6 after 48.5. Sampled data are given as median and IQR. Group differences were tested by the non-parametric Kruskal-Wallis test, individual groups were subjected to subsequent post hoc analysis with the Mann-Whitney $U$ test and Fisher's exact test. $p<0.025$ was considered statistically significant

includes significant hemorrhage is a significant factor in the establishment of a relevant trauma model. No published data deal with a withdrawal greater than $45 \%$ of blood volume and survival beyond $24 \mathrm{~h}$ without retransfusion of shed blood in simple porcine hemorrhage models. Furthermore, no model of combined lung and liver hemorrhage dealing with a withdrawal greater than $45 \%$ and survivals beyond $15.5 \mathrm{~h}$ is described. Models with greater blood loss did not provide observation periods longer than $6 \mathrm{~h}$. In a further study, we proved that withdrawal of $45 \%$ of TBV combined with liver laceration and lung contusion is safe and reproducible for $15.5 \mathrm{~h}$ [1]. Since we added a lower leg fracture and aimed to triple the investigation period, we first decided to keep the hemorrhage and the shock period similar to that of a previous study. This worked reliably for the first 15 pigs. These pigs were proven to react very sensitively, showing arrhythmia and blood loss of more than $45 \%$ TBV or an MAP less than $25 \mathrm{mmHg}$. We slowly extended the borders of hemorrhage to $50 \%$ TBV or an MAP $25 \pm 5 \mathrm{~mm} /$ hg. According to cross-sectional guidelines for the transfusion of red blood cells based on clinical observation and risk factors, a hematocrit value of approximately $15 \%$ (hemoglobin concentration $5.0-4.5 \mathrm{~g} / \mathrm{dL}=3.1-$ $2.8 \mathrm{mmol} / \mathrm{L}$ ) has to be assumed as the critical threshold value for RBC substitution. Blood loss greater than $50 \%$ 
would have surpassed the recommended levels, indicated by the minimal $\mathrm{Hb}$ of $4.6 \mathrm{~g} / \mathrm{dL}$ in group $\mathrm{L}$. In addition, an MAP falling below $20 \mathrm{mmHg}$ for some minutes was shown to promote arrhythmia and frequency of resuscitation. Therefore, we decided to extend the duration of hemorrhagic shock from 90 to $120 \mathrm{~min}$ to additionally aggravate ischemic injury.

As previously mentioned, animal models including withdrawal of blood until a certain endpoint for a defined period of time, followed by retransfusion of shed blood in the subsequent observation period have been described [29]. Cross-sectional recommendations for the transfusion of red blood cells define a hemoglobin concentration of $4.5-5 \mathrm{~g} / \mathrm{dl}$ as the threshold value for transfusion of $\mathrm{RBC}$ in young and healthy subjects. Additionally, a recent publication dealing with the recommendations for red blood cell transfusion in septic patients could not prove a benefit in the transfusion of red blood cells beyond a hemoglobin value of $7 \mathrm{~g} / \mathrm{dl}$ in patients experiencing septic shock. Holst and colleagues provide definitive evidence that a restrictive approach to blood transfusion not only reduced blood use by half, but also did not cause further harm to 998 critically ill patients [30]. In the presented polytrauma model, numerous factors interfere with immune response, inflammation parameters and the circulatory system. Among these are pre-existing medical conditions, iatrogenic trauma due to invasive monitoring, ventilation, and environmental factors. To improve data quality and traceability and to reduce possible interactions, we abstained from RBC transfusions. Furthermore, our pre-existing model which describes similar blood loss without severe complications due to hypovolemia, confirms our approach.

In our model this extended controlled component of bleeding and reperfusion strategy worked reliably.

Liver injury is often used to produce uncontrolled bleeding in animal models. Many combine hemorrhage and grade II-IV liver injuries, but most have a very short shock period of about 5-30 min and a maximum observation time of $7 \mathrm{~h}$ [31-34]. Several studies use fluid resuscitation including blood transfusion $[35,36]$ or surgical treatment, e.g., suturing of liver injury or the use of haemostyptic agents [37]. We decided to produce a grade II (Moore et al.) liver injury to be able to provide a 48.5 -h observation period with liver trauma and impaired liver function. ALT was not elevated and there were no great differences between groups. A tripling of AST indicates severe damage; six animals of 13 in group L and 5 of 7 animals in group $\mathrm{H}$ showed such values at the end of study period. The AST/ALT ratio also suggests severe liver cell damage (Table 2).

However, according to creatinine clearance and urinary output, even the prolonged hemorrhagic shock in group
$\mathrm{H}$ did not lead to clinically significant renal ischemic trauma.

We caused a proximal lower limb fracture because fractured extremities are present in more than $60 \%$ of multiple-trauma patients [12]. This tissue trauma led to significant increases in CK and myoglobin. The differences lacked statistical significance at the late post-traumatic course, perhaps because of small group numbers and large standard deviations; shivering following anesthesia was frequent and may explain elevated CK levels in group $C$. The impact of muscle relaxation has not yet been evaluated.

Our study has several limitations. The animal model is limited in usefulness because of inter-species differences, and the animal welfare committee guidelines restrict sample size. Further, we were unable to achieve a great degree of post-traumatic lung injury. We thought of two ways to improve the lung injury method in advance. On the one hand, we thought of using a more widespread lung trauma at the beginning; bilateral hits were discussed, but this idea was ignored because we wished to have an uninjured lung for data comparison. On the other hand, we tried an aggravation of force by reducing the upper layer of plumb and using a more powerful munition for the captive bolt stunner. Following this, we observed a great amount of tension pneumothoraxes and cardiac arrhythmias due to concomitant heart contusions, resulting in cardiac arrest. Beyond this, a combined repetitive surfactant washout could be promising, but it has to be considered that it would provide a kind of artificial (and not trauma-induced) lung injury. According to the National Trauma Databank, incidence of trauma-related ARDS in trauma patients requiring mechanical ventilation for greater than $48 \mathrm{~h}$ is $6.5 \%$. Hence, to achieve a sufficiently large number of ARDS cases, increase not only in the observation period but also in the number of animals is needed.

As a further limitation, we conclude that any ischemic renal injury was too short to impair the outcome of our study, although changes in renal function may become significant later in the post-traumatic course. Additionally, we have taken into account that creatinine measurement is perhaps not appropriate for detecting early hypoxic-induced renal failure, with the consequence that more sensitive biomarkers for renal injury, such as TIMP2, IGFBP-7 cystatin C, and NGAL have to be considered in further investigation.

Furthermore, we decided to use Ringer's acetate solution for resuscitation. Some trials show that there is evidence that balanced salt solutions are beneficial towards NS as a means of preventing development of hyperchloremic metabolic acidosis. Until now there is no highquality randomized controlled trial comparing different 
balanced crystalloids to each other and, therefore, no consensus exists on a single preferred solution [38, 39]. Nevertheless, even balanced Ringer's acetate solution contains some chloride that can induce a metabolic acidosis.

At last, the trauma groups were too close to each other (in terms of blood loss and duration of shock period) to achieve significant differences. Nevertheless, a higher blood loss of about $60 \%$ with a comparable shock period led to a need for vasopressors and a higher frequency of CPR, which led to a high mortality in previous feasibility tests. As we aimed to obtain $46 \mathrm{~h}$ of observation following trauma, a balance between mortality and reaching a sufficient severity of trauma was hard to find; this was also the case because of differences in shock tolerance between individual animals.

Last but not least it can be assumed that a further extension of the observation period may have revealed greater severity of trauma.

\section{Conclusion}

Our model of polytrauma appears to reflect the mortality and organ failure of polytrauma patients during shock and the intensive care period. It was possible to manage fluids, ventilation and complications according to our goals. Further aggravation of hemorrhagic shock led to increased organ injury and resuscitation rates, thus the degree of trauma must be chosen to reflect the aims of the investigation. This experimental protocol could be of use for the assessment of therapeutic approaches during the post-traumatic period.

\footnotetext{
Abbreviations

ATLS: Advanced Trauma Life Support; BE: base excess; CPR: cardiopulmonary resuscitation; I:E: inspiration-to-expiration ratio; IGFBP-7: insulin-like growth factor-binding protein 7; ISS: injury severity score; MAP: mean arterial pressure; NGAL: neutrophil gelatinase-associated lipocalin; PEEP: positive end-expiratory pressure; PiCCO: pulse contour cardiac output; RBC: red blood cells; RF: respiratory failure; ROSC: return of spontaneous circulation; TBV: total blood volume; TIMP-2: tissue inhibitor of metalloproteinases 2.
}

\section{Authors' contributions}

ED conceived the study, participated in its design and coordination, carried out the study, and is the corresponding author. ST conceived the study, participated in its design and coordination, and helped to draft the manuscript. HF conceived the study and participated in its design and coordination. FM conceived the study, and participated in its design and coordination. SC participated in its design and coordination. SM participated in its design and coordination, and helped to draft the manuscript. WT participated in its design and coordination and carried out the study. DF participated in coordination and carried out the study. VN participated in coordination and carried out the study. EU participated in its design and coordination. PHC conceived the study, and participated in its design and coordination. RS conceived the study, participated in its design and coordination, and helped to draft the manuscript. HK conceived the study, participated in its design and coordination, carried out the study, and helped to draft the manuscript. All authors read and approved the final manuscript.

\section{Author details}

${ }^{1}$ Center for Orthopaedics and Trauma Surgery; University Hospital Giessen and Marburg, Marburg, Germany. ${ }^{2}$ Department of Anaesthesiology and Critical Care, University of Marburg, Marburg, Germany. ${ }^{3}$ Department of Neurosurgery, University of Giessen, Giessen, Germany. ${ }^{4}$ Trauma Department, University of Aachen, Aachen, Germany.

\section{Acknowledgements}

We thank A. Gockel and K. Eisoldt for making substantial contributions in practical acquisition of data.

\section{Compliance with ethical guidelines}

\section{Competing interests}

The authors declare that they have no competing interests.

Received: 6 May 2015 Accepted: 11 August 2015

Published online: 04 September 2015

\section{References}

1. Hildebrand F, Weuster M, Mommsen P, Mohr J, Fröhlich M, Witte I, Keibl C, Ruchholtz S, Seekamp A, Pape HK, Flohe S, van Griensven M. A combined trauma model of chest and abdominal trauma with haemorrhagic shock-description of a new porcine model. Shock. 2012;38(6):664-70.

2. Hildebrand F, Andruszkow H, Huber-Lang M, Pape HC, van Griensven M. Combined hemorrhage/trauma models in pigs-current state and future perspectives. Shock. 2013;40(4):247-73.

3. Kilkenny C, Browne WJ, Cuthill IC, Emerson M, Altman DG. Improving bioscience research reporting: the ARRIVE guidelines for reporting animal research. PLoS Biol. 2010;8(6):1000412. doi:10.1371/journal.pbio.1000412.

4. Bossaert L, O'Connor RE, Arntz HR, Brooks SC, Diercks D, Feitosa-Filho G, Nolan JP, Hoek TL, Walters DL, Wong A, et al. Part 9: acute coronary syndromes: 2010 International consensus on cardiopulmonary resuscitation and emergency cardiovascular care science with treatment recommendations. Resuscitation. 2010;81:175-212.

5. Chapleau W, Al-khatib J, Haskin D, et al. Advanced trauma life support $\left(\right.$ ATLS $\left.^{\circledR}\right)$ : the ninth edition. J Trauma Acute Care Surg. 2013;74(5):1363-6. doi:10.1097/TA.0b013e31828b82f5.

6. ARDSnet, NIH, nhlbi, ards clinical network mechanical ventilation protocol summary. http://www.ardsnet.org/. Accessed Jun 2013

7. Gustilo RB, Mendoza RM, Williams DN. Problems in the management of type III (severe) open fractures: a new classification of type III open fractures. J Trauma. 1984:24:742-6.

8. Frith D, Cohen MJ, Brohi K. Animal models of trauma-induced coagulopathy. Thromb Res. 2012;129(5):551-6.

9. Burns JW, Baer L, Darlington DN, Dubick MA, Wade CE. Screening of potential small volume resuscitation products using a severe hemorrhage sedated swine model. Int J Burns Trauma. 2012;2(1):59-67.

10. Grottke $O$, Braunschweig T, Philippen B, Gatzweiler KH, Gronloh N, Staat $M$, Rossaint R, Tolba R. A new model for blunt liver injuries in the swine. Eur Surg Res. Europaische chirurgische Forschung. Recherches chirurgicales europeennes. 2010;44(2):65-73 (18 Copyright $\odot 2013$ by the Shock Society).

11. Majde JA. Animal models for hemorrhage and resuscitation research. J Trauma. 2003;54(5 Suppl):S100-5.

12. Mand C, Müller T, Lefering R, Ruchholtz S, Kühnen CA. A comparison of the treatment of severe injuries between the former East and West German states. Dtsch Arztebl Int. 2013;110(12):203-10. doi:10.3238/ arztebl.2013.0203.

13. De Castro GP, Dowling MB, Kilbourne M, Keledjian K, Driscoll IR, Raghavan SR, Hess JR, Scalea TM, Bochicchio GV. Determination of efficacy of novel modified chitosan sponge dressing in a lethal arterial injury model in swine. J Trauma Acute Care Surg. 2012;72(4):899-907.

14. Mueller GR, Pineda TJ, Xie HX, Teach JS, Barofsky AD, Schmid JR, Gregory $\mathrm{KW}$. A novel sponge based wound stasis dressing to treat lethal noncompressible hemorrhage. J Trauma Acute Care Surg. 2012;73(2 Suppl. 1):134-9. 
15. Martinowitz U, Holcomb JB, Pusateri AE, Stein M, Anaca N, Freidmann M, Macaitis JM, Castel D, Heldner U, Hess JR. Intravenous rFVIla administered for hemorrhage control in hypothermic coagulopathic swine with grade V liver injuries. J Trauma. 2001;50(4):721-9.

16. Smith J, Greaves I, Porter K. Oxford desk reference-major trauma. Oxford University Press 26.4.

17. Hofmaier F, Dinger K, Braun R, Sterner-Kock A. Range of blood lactate values in farm pigs prior to experimental surgery. Lab Anim. 2013;47(2):1302. doi:10.1177/0023677213476857 (Epub 2013 Mar 11)

18. Scribner DM, Witkowski NE, Mulier KE, Lusczek ER, Wasilunk KR, Beilaman GJ. Liver metabolic changes identify biochemical pathways in hemorrhagic shock. J Surg Res. 2010;164(1):e131-9.

19. Miller PR, Croce MA, Kilgo PD, Scott J, Fabian TC. Acute respiratory distress syndrome in blunt trauma: identification of independent risk factors. Am Surg. 2002;68(10):845-50.

20. Navarrete-Navarro P, Rivera-Fernández R, Rincón-Ferrari MD, GarcíaDelgado M, Muñoz A, Jiménez JM, Ortega FJ, García DM. Early markers of acute respiratory distress syndrome development in severe trauma patients. GITAN multicenter project. J Crit Care. 2006;21(3):253-8.

21. Takasu A, Norio H, Gotoh Y, Sakamoto T, Okada Y. Effect of induced hypothermia on short-term survival after volume-controlled hemorrhage in pigs. Resuscitation. 2003;56(3):319-28.

22. Wladis A, Hjelmqvist $H$, Brismar B, Kjellstrom BT. Acute metabolic and endocrine effects of induced hypothermia in hemorrhagic shock: an experimental study in the pig. J Trauma. 1998;45(3):527-33.

23. Dalle Lucca JJ, Simovic M, Li Y, Moratz C, Falabella M, Tsokos GC. Decay accelerating factor mitigates controlled hemorrhage-instigated intestinal and lung tissue damage and hyperkalemia in swine. J Trauma. 2011;71(Suppl 1):S151-60.

24. Segal N, Rees J, Convertino VA, Metzger A, Zarama D, Voulgaropoulos L, McKnite SH, Yannopoulos D, Tang W, Vicaut E, et al. Improving microcirculation with therapeutic intrathoracic pressure regulation in a porcine model of hemorrhage. Resuscitation. 2011;82(Suppl 2):S16-22.

25. Savage SA, Fitzpatrick CM, Kashyap VS, Clouse WD, Kerby JD. Endothelial dysfunction after lactated Ringer's solution resuscitation for hemorrhagic shock. J Trauma. 2005;59(2):284-90.

26. Martini WZ, Cortez DS, Dubick MA, Park MS, Holcomb JB. Thrombelastography is better than PT, aPTT, and activated clotting time in detecting clinically relevant clotting abnormalities after hypothermia, hemorrhagic shock and resuscitation in pigs. J Trauma. 2008;65(3):535-48.

27. Doucet JJ, Hoyt DB, Coimbra R, Schmid-Schonbein GW, Junger WG, Paul LW, Loomis WH, Hugli TE. Inhibition of enteral enzymes by enteroclysis with nafamostat mesilate reduces neutrophil activation and transfusion requirements after hemorrhagic shock. J Trauma. 2004;56(3):501-10

\section{(discussion 510-511)}

28. Noritomi DT, Pereira AJ, Bugano DD, Rehder PS, Silva E. Impact of Plasma-Lyte $\mathrm{pH} 7.4$ on acid-base status and hemodynamics in a model of controlled hemorrhagic shock. Clinics. 2011;66(11):1969-74.
29. Hawksworth JS, Graybill JC, Brown TS, Wallace SM, Davis TA, Tadaki DK, Elster EA. Lymphocyte modulation with FTY720 improves hemorrhagic shock survival in swine. PLoS One. 2012;7(4):e34224.

30. Holst LB, Haase N, Wetterslev J. Lower versus higher hemoglobin threshold for transfusion in septic shock. N Engl J Med. 2014;371(15):1381-91. doi:10.1056/NEJMoa1406617 (Epub 2014 Oct 1)

31. Stadlbauer KH, Wagner-Berger HG, Raedler C, Voelckel WG, Wenzel V, Krismer AC, Klima G, Rheinberger K, Nussbaumer W, Pressmar D, et al. Vasopressin, but not fluid resuscitation, enhances survival in a liver trauma model with uncontrolled and otherwise lethal hemorrhagic shock in pigs. Anesthesiology. 2003;98(3):699-704.

32. Watters JM, Brundage SI, Todd SR, Zautke NA, Stefater JA, Lam JC, Muller PJ, Malinoski D, Schreiber MA. Resuscitation with lactated Ringer's does not increase inflammatory response in a swine model of uncontrolled hemorrhagic shock. Shock. 2004;22(3):283-7.

33. Stern S, Rice J, Philbin N, McGwin G, Arnaud F, Johnson T, Flournoy WS, Ahlers S, Pearce LB, McCarron R, et al. Resuscitation with the hemoglobin based oxygen carrier, HBOC-201, in a swine model of severe uncontrolled hemorrhage and traumatic brain injury. Shock. 2009;31(1):64-79.

34. Holcomb JB, Pusateri AE, Harris RA, Reid TJ, Beall LD, Hess JR, MacPhee MJ. Dry fibrin sealant dressings reduce blood loss, resuscitation volume, and improve survival in hypothermic coagulopathic swine with grade $V$ liver injuries. J Trauma. 1999;47(2):233-40 (discussion 240-242).

35. Alam HB, Hamwi KB, Duggan M, Fikry K, Lu J, Fukudome EY, Chong W, Bramos A, Kim K, Velmahos G. Hemostatic and pharmacologic resuscitation: results of a long-term survival study in a swine polytrauma model. J Trauma. 2011;70(3):636-45.

36. Teranishi K, Scultetus A, Haque A, Stern S, Philbin N, Rice J, Johnson T, Auker C, McCarron R, Freilich D, et al. Traumatic brain injury and severe uncontrolled haemorrhage with short delay pre-hospital resuscitation in a swine model. Injury. 2012;43(5):585-93.

37. Executive Committee of the German Medical Association on the recommendation of the Scientific Advisory Board. The cross-sectional guidelines for therapy with blood components and plasma derivates-4th revised edition "transfusion medicine and hemotherapy". 2009;36(6):345492 and 2011;38:71. http://content.karger.com/ProdukteDB/produkte. asp?issn $=1660-3796 \&$ volume $=36 \&$ issue $=6$.

38. Lira A, Michael R Pinsky. Choices in fluid type and volume during resuscitation: impact on patient outcomes. Ann Intensive Care. 2014;4:38 doi:10.1186/s13613-014-0038-4. (Published online 2014 Dec 4, PMCID: PMC4298675)

39. Burdett $\mathrm{E}$, et al. Perioperative buffered versus non-buffered fluid administration for surgery in adults. Cochrane Database Syst Rev. 2012;12:CD004089.

\section{Submit your next manuscript to BioMed Central and take full advantage of:}

- Convenient online submission

- Thorough peer review

- No space constraints or color figure charges

- Immediate publication on acceptance

- Inclusion in PubMed, CAS, Scopus and Google Scholar

- Research which is freely available for redistribution

Submit your manuscript at 